\title{
RANCANG BANGUN APLIKASI PENJUALAN DAN PERSEDIAAN BARANG BERBASIS DESKTOP PADA CV.SANTOEN
}

\author{
Rismawati Helda Diana \\ Universitas Indraprasta PGRI \\ Jl. Raya Tengah No. 80, Kel. Gedong, Kec. Pasar Rebo, Jakarta Timur \\ rismadiana88@gmail.com
}

\begin{abstract}
ABSTRAK
Penelitian dilakukan di CV. SANTOEN, Kota Depok yang merupakan suatu bentuk badan usaha yang bergerak dibidang percetakan (Digital Printing). Adapun, jasa yang diberikan yaitu photocopy, Digital Printing, Penjilidan buku, souvenir dan alat tulis kantor. Dalam hal penjualan alat tulis kantor, CV. SANTOEN masih belum menggunakan komputer dalam penginputan data yang masuk ataupun keluar, sehingga dalam input data masih cara manual atau masih tertulis dengan menggunakan buku dan catatan. Hal ini menyebabkan proses pencarian data dan pembuatan laporan menjadi tidak tepat dan tidak akurat. Tujuan penelitian yaitu pembuatan sistem yang berbentuk rancang bangun aplikasi penjualan dan persediaan barang yang dapat digunakan untuk memudahkan CV. SANTOEN dalam hal pengolahan data-data usaha seperti penyimpanan, pencarian data, pembuatan laporan dan mengenai transaksi yang dilakukan oleh CV. SANTOEN. Metode penelitian yang digunakan adalah kualitatif deskriptif dan metode $R \& D$ (Reseach and Development). Hasil dari penelitian adalah Rancang Bangun Aplikasi Penjualan dan Persediaan Barang Berbasis Desktop dengan menggunakan Java Netbeans dan Database MySQL.
\end{abstract}

Kata Kunci: Aplikasi, Penjualan dan Persediaan, Barang, Java, MySQL

\section{ABSTRACT}

The research was conducted at CV. SANTOEN, Depok City which is a form of business entity engaged in printing (Digital Printing) while the services provided are photocopying, Digital Printing, bookbinding, souvenirs and office stationery. In terms of selling office stationery, CV. SANTOEN still does not use a computer in inputting incoming or outgoing data, so that data input is still manual or still written using books and notes. This causes the process of searching for data and making reports to be inaccurate and inaccurate. The purpose of the research is to create a system in the form of a sales application design and inventory that can be used to facilitate $C V$. SANTOEN in terms of processing business data such as storage, data retrieval, report generation and regarding transactions made by $C V$. SANTOEN. The research method used is descriptive qualitative and $R \& D$ (Reseach and Development) method. The result of the research is the Design and Build of Desktop-Based Sales and Inventory Applications using Java Netbeans and MySQL Database.

Key Word: Applications, Sales and Inventory, Items, Java, MySQL

\section{PENDAHULUAN}

CV. SANTOEN merupakan suatu bentuk badan usaha yang bergerak dibidang percetakan (Digital Printing) adapun jasa yang diberikan yaitu photocopy, Digital Printing, Penjilidan buku, souvenir dan alat tulis kantor. Penjualan adalah sistem memperjual belikan barang dan jasa (Masrulin, 2019). Persediaan adalah sejumlah besar produk manufaktur, bahan baku, dan barang dalam proses yang dimiliki oleh perusahaan untuk dijual atau diproses lebih lanjut (Rudianto, 2012). Aplikasi adalah perintah yang dieksekusi oleh mesin komputer dalam menyimpan suatu dokumen (Eko Sujatmiko, 2012).
Berdasarkan kasus tersebut, sehingga CV. SANTOEN memerlukan suatu sistem data penjualan yang dapat menciptakan laporanlaporan penjualan barang tiap harinya atau bulanan, laporan stok barang, laporan data barang, serta laporan pembelian barang masuk dalam proses pengolahan informasi penjualan serta menanggulangi masalah-masalah yang terdapat pada CV. SANTOEN.

Dengan ini penulis membuat Rancang Bangun Aplikasi Penjualan dan Persediaan Barang Berbasis Desktop pada CV. SANTOEN diharapkan memudahkan pemilik untuk meningkatkan pelayanan kepada customer serta pula menciptakan laporanlaporan yang bisa digunakan untuk menganalisa informasi penjualan pada 
periode sebelumnya sebagai dasar untuk pengambilan keputusan

Rancang bangun adalah suatu kegiatan dalam bentuk menerjemahkan perangkat lunak dan memperbaiki sistem yang sudah ada (Zulfiandri, 2016). Java adalah sekumpulan teknologi untuk membuat dan menjalankan perangkat lunak pada komputer standalone ataupun java platform (Rosa A.S dan Shalahuddin, 2014)Database MySQL merupakan sebuah database server $S Q L$ multiuser dan multi-threaed(Badiyanto, 2013)Netbeans merupakan sebuah aplikasi Integrated Development Environment (IDE) yang berjalan diatas Swing (Nofriadi, 2015).

Tujuan penelitian ini ialah rancang bangun aplikasi penjualan dan persediaan barang yang meliputi beberapa proses transaksi antara lain proses mengolah data barang, karyawan, pelanggan, supplier, barang masuk, pemesanan dan penjualan. Serta pembuatan laporan-laporan transaksi antara lain laporan data barang, stok barang, penjualan, serta pembelian.

\section{METODE PENELITIAN}

Penelitian ini menggunakan metode $R \& D$ (Reseach and Development). Metode $R \& D$ ini seringkali digunakan sebagai proses penelitian yang bertujuan untuk menghasilkan produk, yang langkah-langkahnya adalah analisis, perancangan, penerapan, dan pemeliharaan(Kristanto, 2013).

Metode yang digunakan pengumpulan data serta pengambilan keterangan yang dibutuhkan untuk merancang program dalam penelitian ini dilakukan dengan cara:

1. Sumber Data Primer: Data primer data berupa catatan dari hasil wawancara dengan informan yang dijadikan sampel penelitian. penulis mengumpulkan data primer dengan menggunakan teknik, antara lain sebagai berikut:

a. Observasi (Pengamatan): Pengamatan dilakukan dengan mengamati langsung dengan kunjungan ke CV. SANTOEN. Adapun pengamatan dilakukan pada hari biasa dan hari libur agar bisa membedakan perilaku dari pengunjung di CV. SANTOEN.

b. Wawancara: Wawancara ini dilakukan dengan tanya jawab kepada pihak yang terkait, yaitu ke pemilik CV.
SANTOEN dengan mengajukan beberapa pertanyaan yang ada kaitannya dengan kebutuhan penelitian.

c. Dokumentasi: Mengumpulkan data dengan cara mencatat semua data yang ada pada dokumen atau arsip di CV. SANTOEN. Penelitian ini dilakukan di CV. SANTOEN yang beralamat Jl. H. Amat No.09, Kukusan, Kecamatan Beji, Kota Depok, Telp: $087889513410 . \quad$ Pelaksanaan penelitian ini dilakukan dalam waktu empat bulan, mulai bulan Maret 2021 sampai dengan Juni 2021.

2. Sumber Data Sekunder: Teknik pengumpulan data dengan cara studi pustaka yaitu, mengumpulkan data dan mempelajari yang berhubungan dengan permasalahan yang akan diteliti.

Dalam pengembangan sistem yang terdapat pada CV. SANTOEN, penulis menggunakan metodologi waterfall. Waterfall sering juga disebut model sekuensial linier atau alur hidup klasik (classic life cycle(A. Rosa S dan Shalahuddin, 2018).

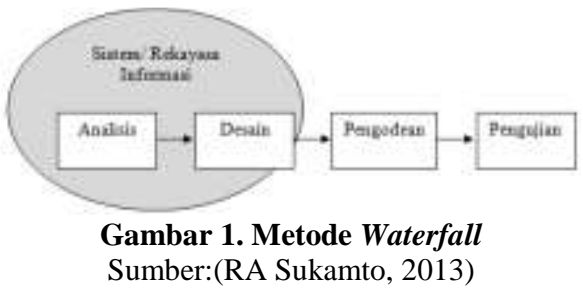

HASIL DAN PEMBAHASAN

Berdasarkan hasil penelitian kasus sebelumnya, peneliti menaruh analisa konflik berdasarkan sistem pengelolaan data diantaranya:

1. Membuat Rancang Bangun Aplikasi Penjualan dan Persediaan barang yang berbasis Desktop pada CV. SANTOEN agar dapat berjalan lebih efektif.

2. Menggunakan database MySQL, sebagai media penyimpanan data agar data dapat disimpan dengan aman dan tidak terjadi kehilangan data.

3. Menggunakan iReport pada netbeans, agar pembuatan laporan lebih efektif dan efisien. Penggunaan iReport juga mengurangi terjadinya kesalahan pada pembuatan laporan. 
Kamus data adalah kumpulan beberapa elemen yang mengalir pada sistem perangkat lunak sehingga masukan (input) dan keluaran (output) dapat dipahami secara umum (A. Rosa S dan Shalahuddin, 2018).

\section{Diagram Konteks Sistem}

Berikut ialah gambaran sistem pada rancang bangun aplikasi penjualan dan persediaan barang pada CV. SANTOEN dalam bentuk diagram konteks.



Gambar 2. Diagram Konteks yang Diusulkan

\section{(ERD) Entity Relationship Diagram}

$E R D$ digunakan untuk pemodelan basis data relasional. Sehingga penyimpanan basis data menggunakan sistem OODBMS(Rosa, A. Shalahuddin, 2013).

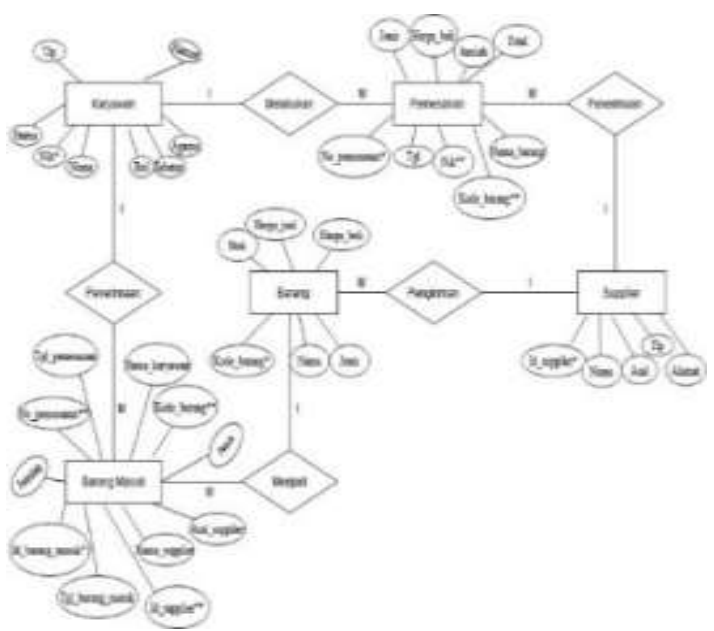

Gambar 3. (ERD) Entity Relationship Diagram

\section{Tampilan Layar}

Berikut ini adalah tampilan layar yang telah diimplementasikan serta pengujian pada sistem yang sudah dirancang serta dibuat dengan menggunakan bahasa pemrograman $J A V A$ serta sistem database nya ialah MYSQL.

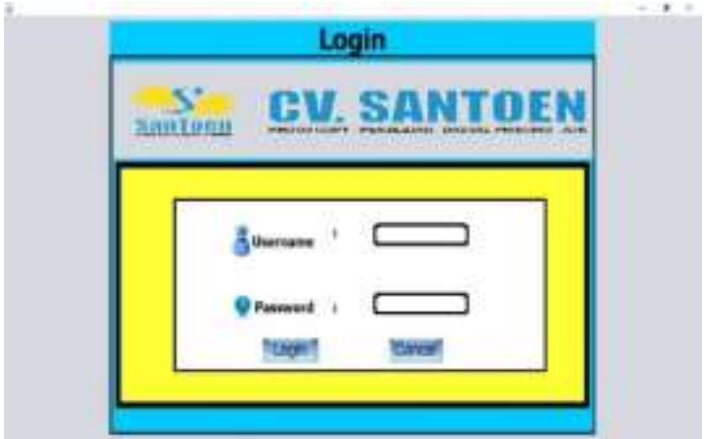

Gambar 4. Tampilan Login

Tampilan menu login dari sistem yang dirancang diatas adalah untuk melakukan akses sebelum masuk ke dalam menu utama serta menu-menu yang terdapat pada sistem.

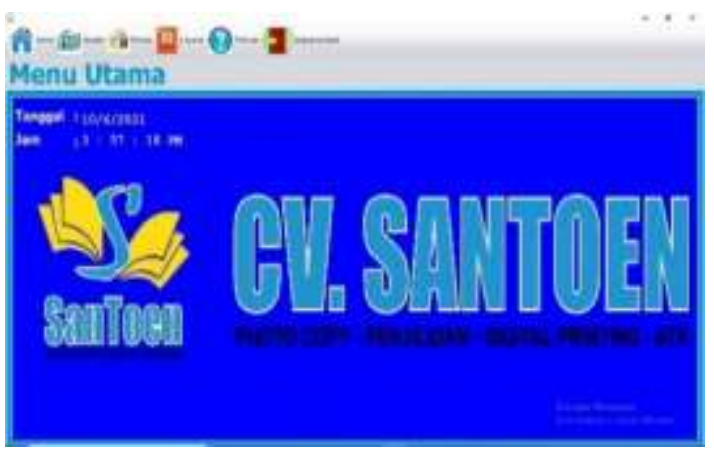

Gambar 5. Tampilan Menu Utama

Tampilan menu utama dari sistem yang dirancang diatas adalah untuk memilih menu sesuai dengan kegiatan proses pekerjaan yang dibutuhkan. Didalamnya ada beberapa sub menu yang dirancang seperti menu data master, menu proses atau transaksi, dan menu laporan.

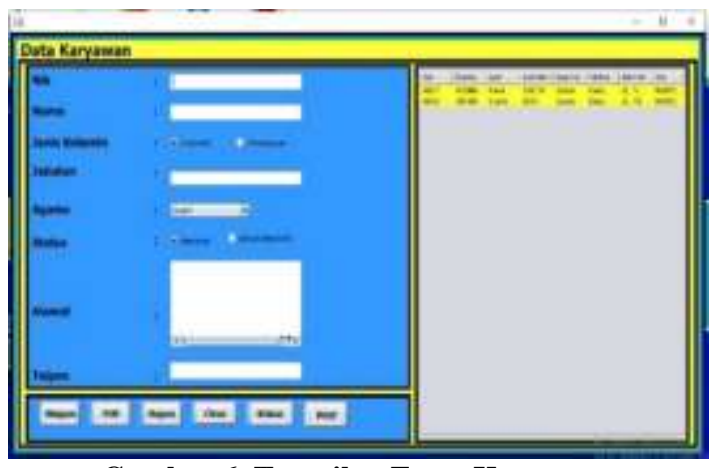

Gambar 6. Tampilan Form Karyawan

Tampilan menu form data karyawan diatas mempunyai fungsi untuk melakukan adanya proses penginputan data karyawan. 


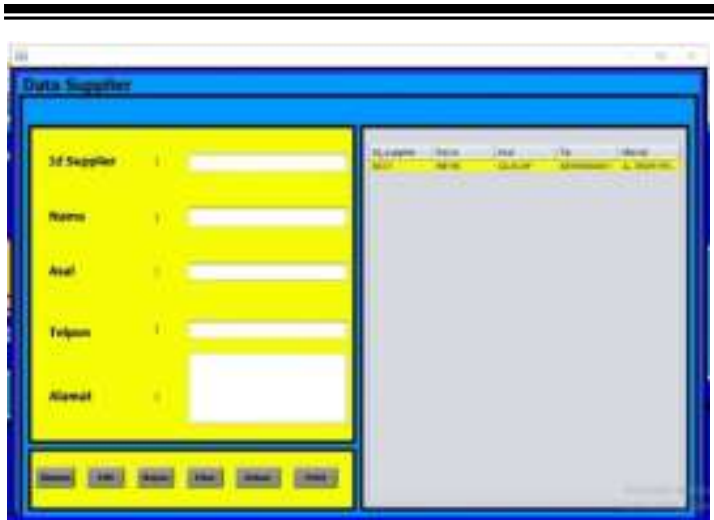

Gambar 7. Tampilan Form Supplier

Tampilan menu form data supplier diatas mempunyai fungsi untuk melakukan adanya proses penginputan data supplier.

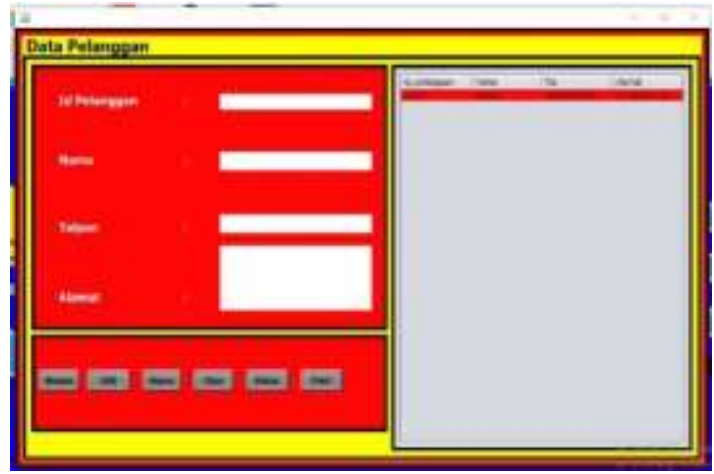

Gambar 8. Tampilan Form Pelanggan

Tampilan menu form data pelanggan diatas mempunyai fungsi untuk melakukan adanya proses penginputan data pelanggan.

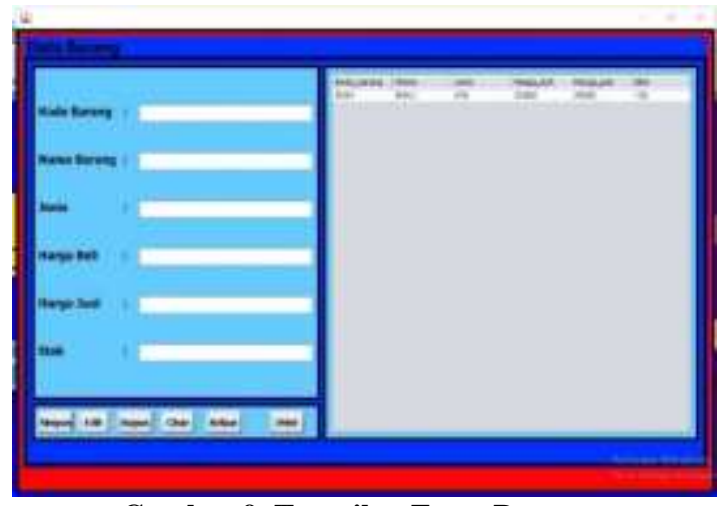

Gambar 9. Tampilan Form Barang

Tampilan menu form data barang diatas mempunyai fungsi untuk melakukan adanya proses penginputan data barang.

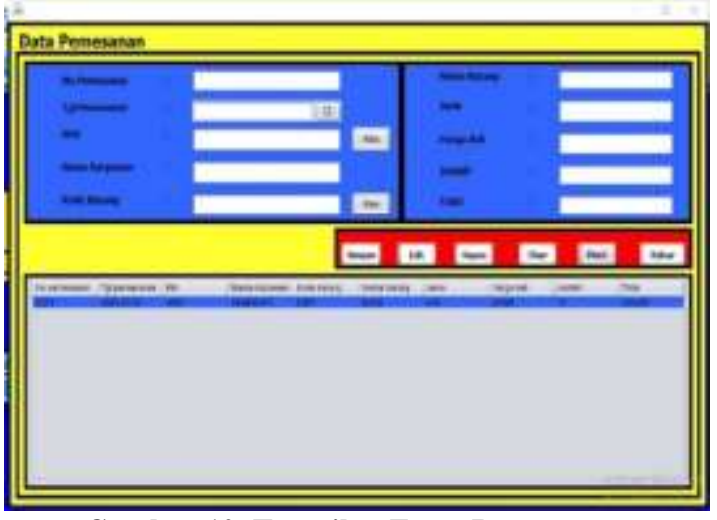

Gambar 10. Tampilan Form Pemesanan

Tampilan menu form data pemesanan barang diatas mempunyai fungsi untuk melakukan adanya proses penginputan data pemesanan barang.

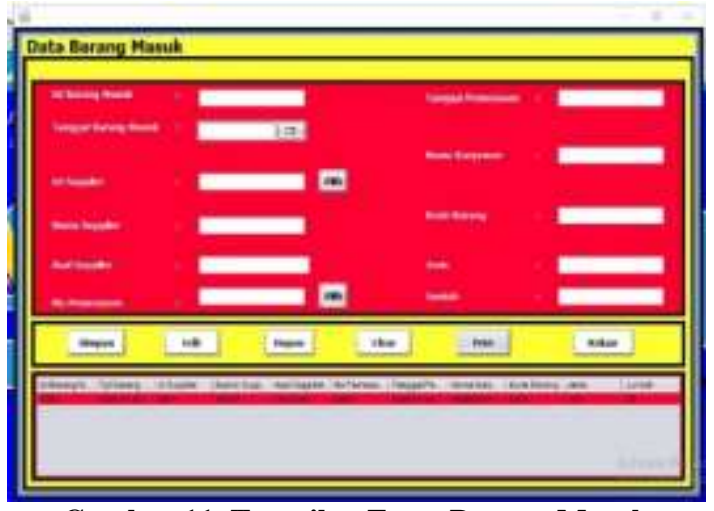

Gambar 11. Tampilan Form Barang Masuk

Tampilan menu form data barang masuk diatas mempunyai fungsi untuk melakukan adanya proses penginputan data barang masuk.

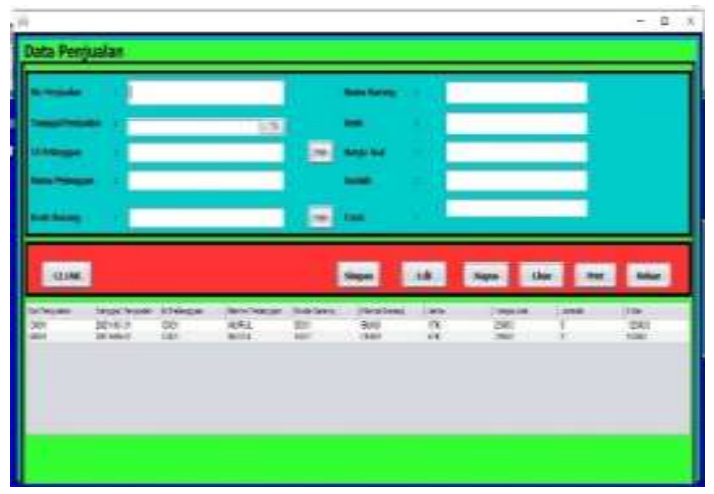

Gambar 12. Tampilan Form Penjualan

Tampilan menu form data penjualan diatas mempunyai fungsi untuk mengelola data transaksi penjualan suatu barang. 


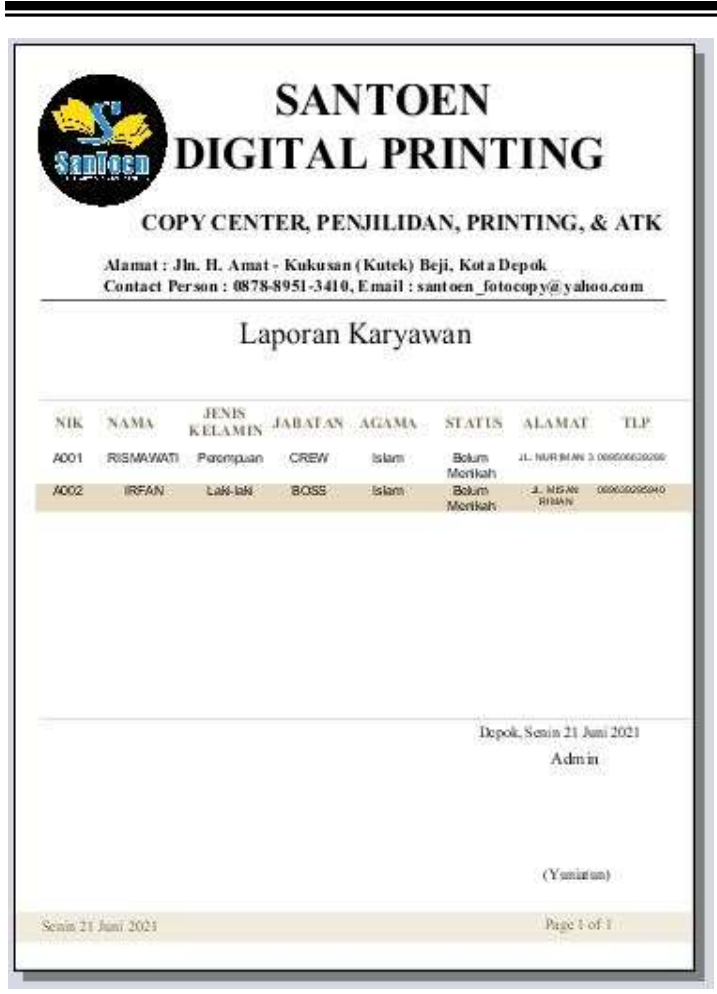

Gambar 13. Tampilan Laporan Data Karyawan

Tampilan diatas merupakan tampilan Form karyawan dari menu data master yang akan dijadikan laporan data karyawan.

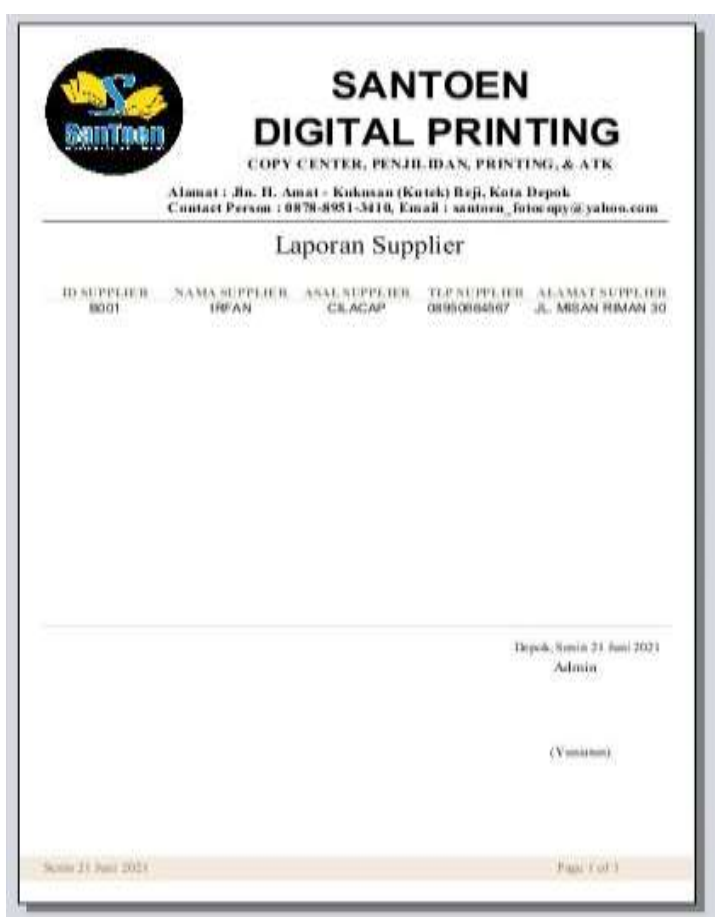

Gambar 14. Tampilan Laporan Data Supplier

Tampilan diatas merupakan tampilan Form supplier dari menu data master yang akan dijadikan laporan data supplier.

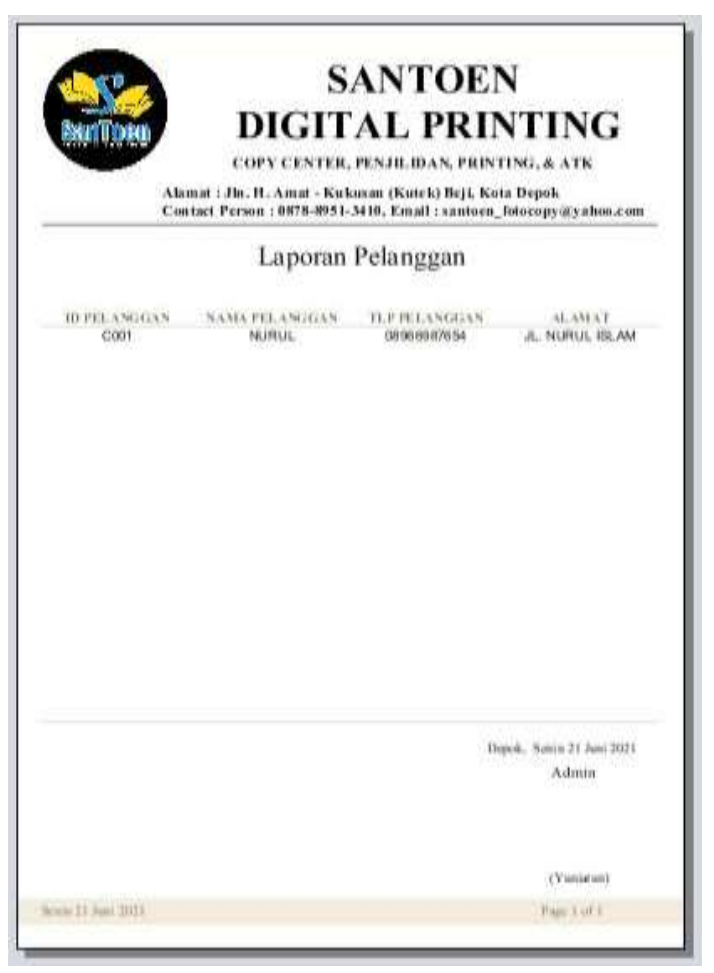

Gambar 15. Tampilan Laporan Data Pelanggan

Tampilan diatas merupakan tampilan Form pelanggan dari menu data master yang akan dijadikan laporan data pelanggan.



Gambar 16. Tampilan Laporan Data Barang

Tampilan diatas merupakan tampilan Form barang dari menu data master yang akan dijadikan laporan data barang. 


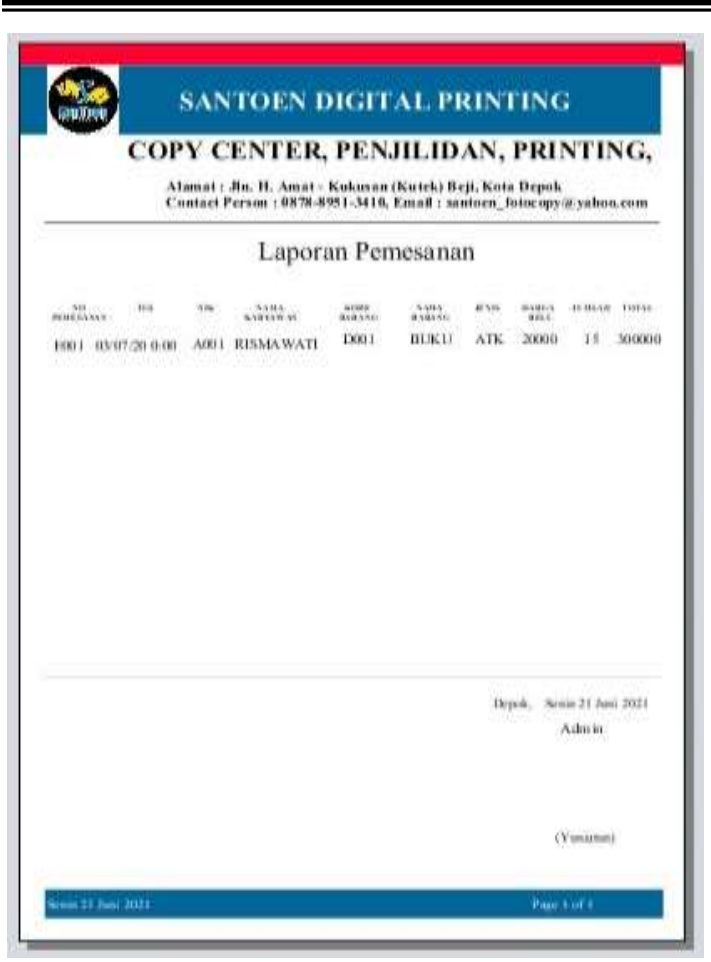

Gambar 17. Tampilan Laporan Data Pemesanan

Tampilan diatas merupakan tampilan Form pemesanan dari menu data transaksi atau proses yang akan dijadikan laporan data pemesanan barang.

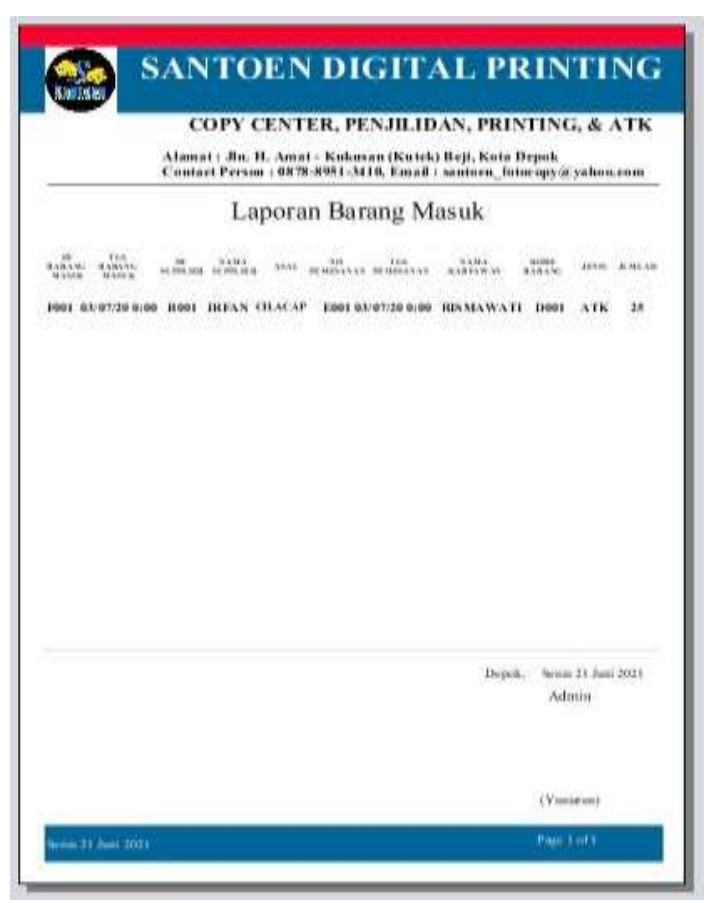

Gambar 18. Tampilan Laporan Data Barang Masuk

Tampilan diatas merupakan tampilan Form barang masuk dari menu data transaksi atau proses yang akan dijadikan laporan data barang masuk.

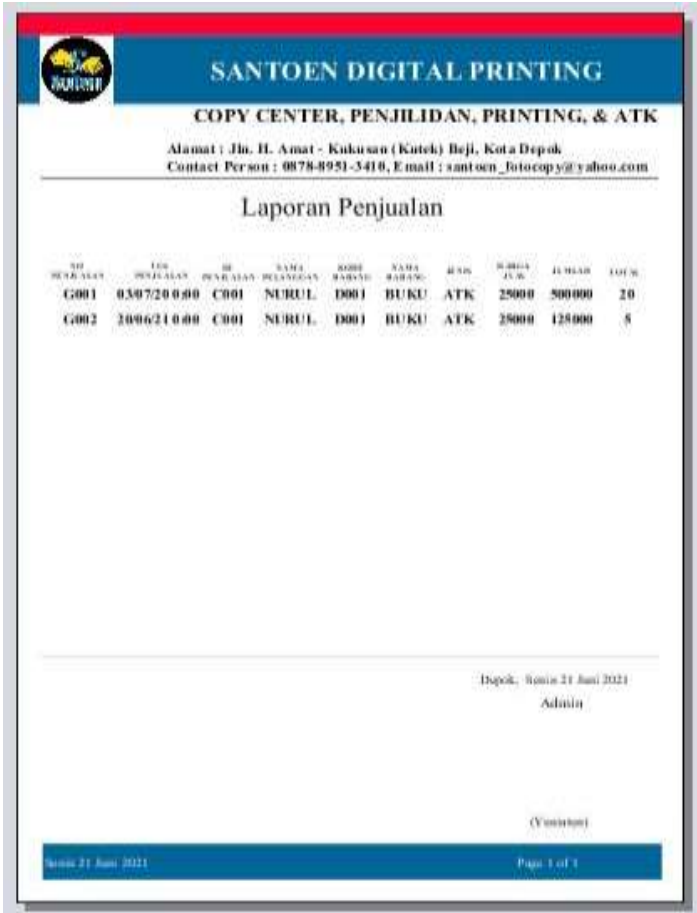

Gambar 19. Tampilan Laporan Data Penjualan

Tampilan diatas merupakan tampilan Form penjualan dari menu data transaksi atau proses yang akan dijadikan laporan data penjualan barang.

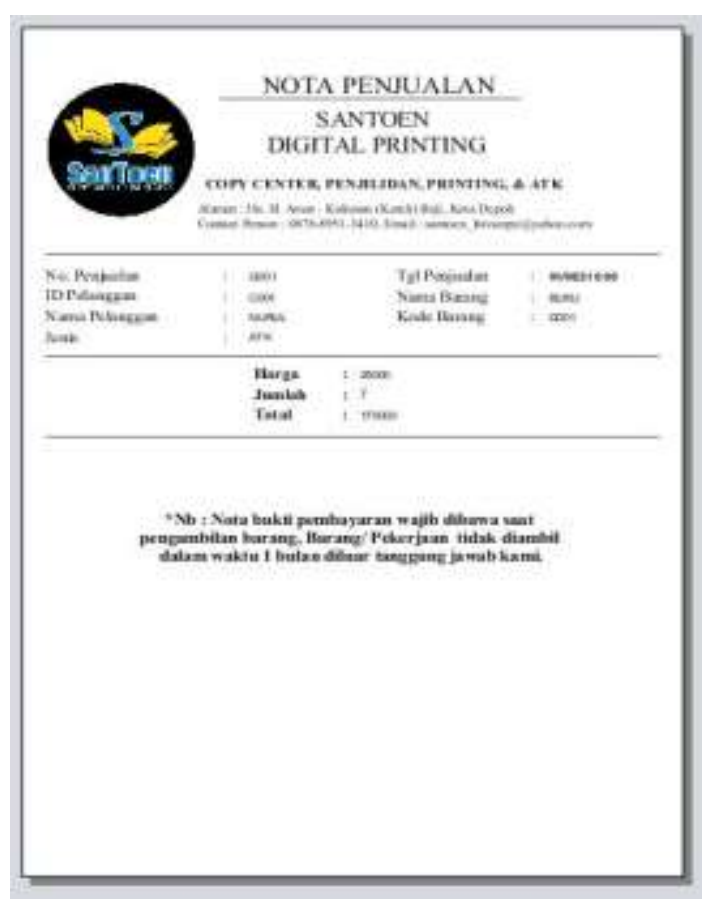

Gambar 20. Tampilan Nota Penjualan

Tampilan diatas merupakan tampilan Nota penjualan dari menu data transaksi penjualan untuk tanda bukti pembelian customer. 


\section{SIMPULAN DAN SARAN}

Berdasarkan penelitian yang sudah dicoba penulis mengenai rancang bangun aplikasi penjualan dan persediaan barang pada $\mathrm{CV}$. SANTOEN dapat diambil kesimpulan sebagai berikut: Mempermudah pekerjaan karyawan CV. SANTOEN untuk mengolah data penjualan dan mempercepat pembuatan laporan. Dengan dibuatnya aplikasi ini, data penyimpanan akan lebih aman dan meminimalisir terjadinya kehilangan data, karena penyimpanan sudah terkomputerisasi menggunakan database dan tidak dilakukan secara manual.

Berdasarkan hasil evaluasi terhadap rancang bangun aplikasi penjualan dan persediaan barang yang penulis bangun terdapat beberapa saran untuk pengembangan diantaranya adalah: Rancang bangun aplikasi penjualan dan persediaan barang ini akan lebih baik ditambahkan layanan virtual banking untuk mempermudah proses pembayaran. Rancang bangun aplikasi penjualan dan persediaan barang diharapkan berupa web, agar dapat memudahkan dalam melakukan pemesanan dan penjualan tanpa harus datang langsung.

\section{DAFTAR PUSTAKA}

A. Rosa S dan Shalahuddin, M. (2018). Rekayasa Perangkat Lunak (Terstruktur dan Berorientasi Objek) Edisi Revisi. Informatika.

Badiyanto. (2013). Buku Pintar Framework Yii Cara Mudah Membangun Aplikasi Web PHP (1st ed.). Mediakom.

Eko Sujatmiko. (2012). Kamus Teknologi Informasi dan Komunikasi (1st ed.). PT. Aksarra Sinergi Media.

Kristanto, A. (2013). Perancangan Sistem Informasi dan Aplikasinya.

Masrulin, U. (2019). Penjualan Minyak Kutus-kutus melalui Sistem Reseller. Politeknik NSC Surabay Repository. repository.nscpolteksby.ac.id

Nofriadi. (2015). Java Fundamental dengan Netbeans 8.0.2. DeePublish.

RA Sukamto, M. S. (2013). Rekayasa Perangkat Lunak. Informatika.

Rosa A.S dan Shalahuddin, M. (2014). Rekayasa Perangkat Lunak Terstruktur Dan Berorientasi Objek. Informatika.

Rudianto. (2012). Pengantar Akuntansi Konsep dan Teknik Penyusunan Laporan Keuangan Adaptasi IFRS. Erlangga.

Zulfiandri. (2016). Rancang bangun aplikasi poliklinik gigi (studi kasus : poliklinik gigi kejaksaan agung ri). Depok: Universitas Gunadarma, 8(Kommit), 473-482. https://doi.org/10.1210/en.2005-0771 